Figure S5. Map and logs of slot trench indicating right-lateral slip in the vicinity of the Boundary trench.

\section{UNIT DESCRIPTIONS}

$8 / 7$

Unit 8-Silty pebbly sand and gravel (modern soil horizons developed on root-stirred sediment; late Holocene)

Unit 7-Massive to weakly bedded sandy pebble gravel (glaciofluvial channel deposits, late Pleistocene)

$7 a-$ Weakly bedded sandy pebble gravel (glaciofluvial)

Unit 6-Massive to crudely bedded gravelly silt and sand (glaciofluvial and till deposits, late Pleistocene)

6e-Crudely bedded, pebbly fine sandy silt (glaciofluvial)

6a-Massive, unsorted, pebbly and cobbly silty fine sand (till)

Unit 5-Well-bedded, pebbly silt to fine sand (proglacial lacustrine(?) or fluvial deposit, late Pleistocene)

2 Unit 2-Interbedded sandstone, pebbly sandstone, carbonaceous shale, and coal; highly sheared, with convoluted bedding and abundant clayey gouge zones; probably Rocks of Bulson Creek (Oligocene-Eocene)

1 Unit 1-Interbedded fine-medium sandstone, pebbly sandstone carbonaceous shale; highly weathered; probably Chuckanut Formation (Eocene)

\section{SYMBOLS}

Fault, Quaternary; dashed where inferred

Fault, in bedrock; dashed where inferred Contacts; sharp or distinct

Large roots, wood, or charcoal, and areas disturbed by modern roots Selected pebbles, cobbles, and boulders

Piercing point

\section{NOTE FROM BOUNDARY SLOT TRENCH, NORTH WALL}

$\mathrm{n} 1$-Fault intersects wall at very shallow angle
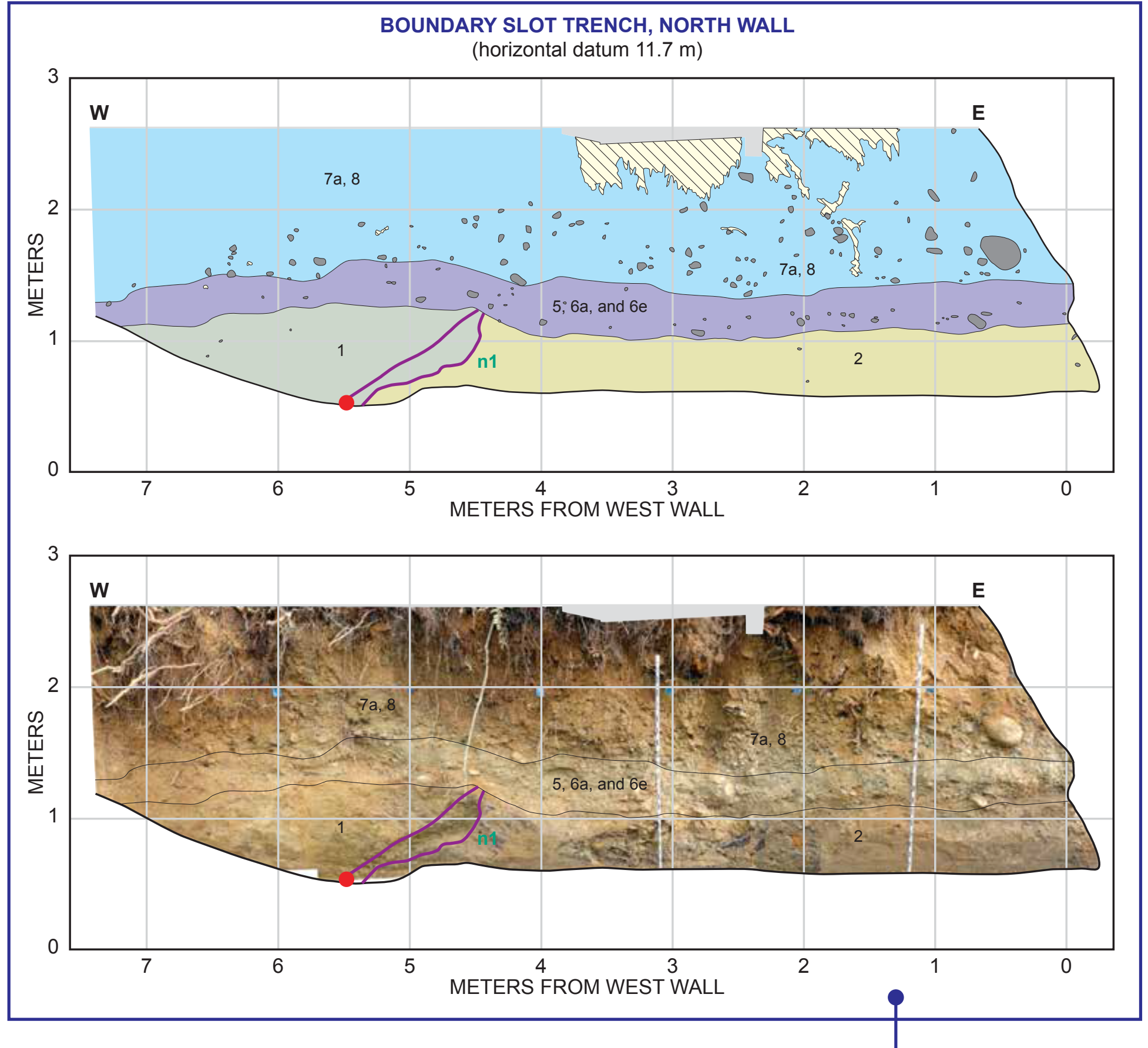

BOUNDARY SLOT TRENCH OBLIQUE VIEW OF BACK (WEST) WALL

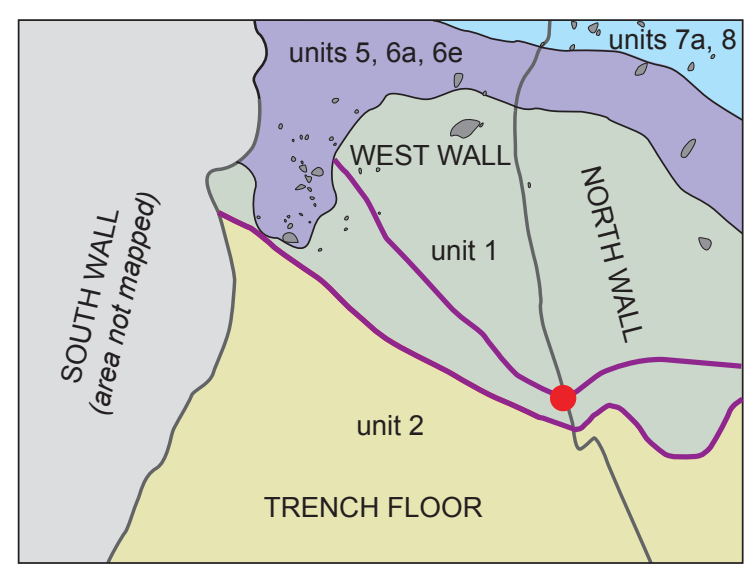

1 meter $\_$

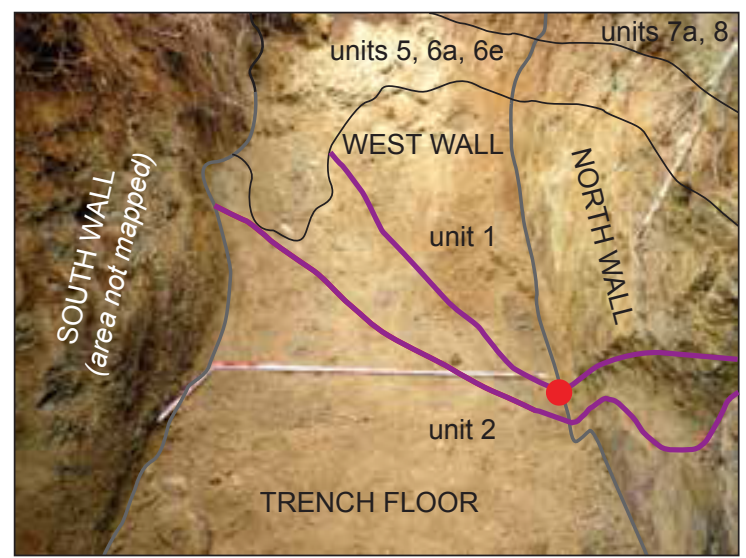

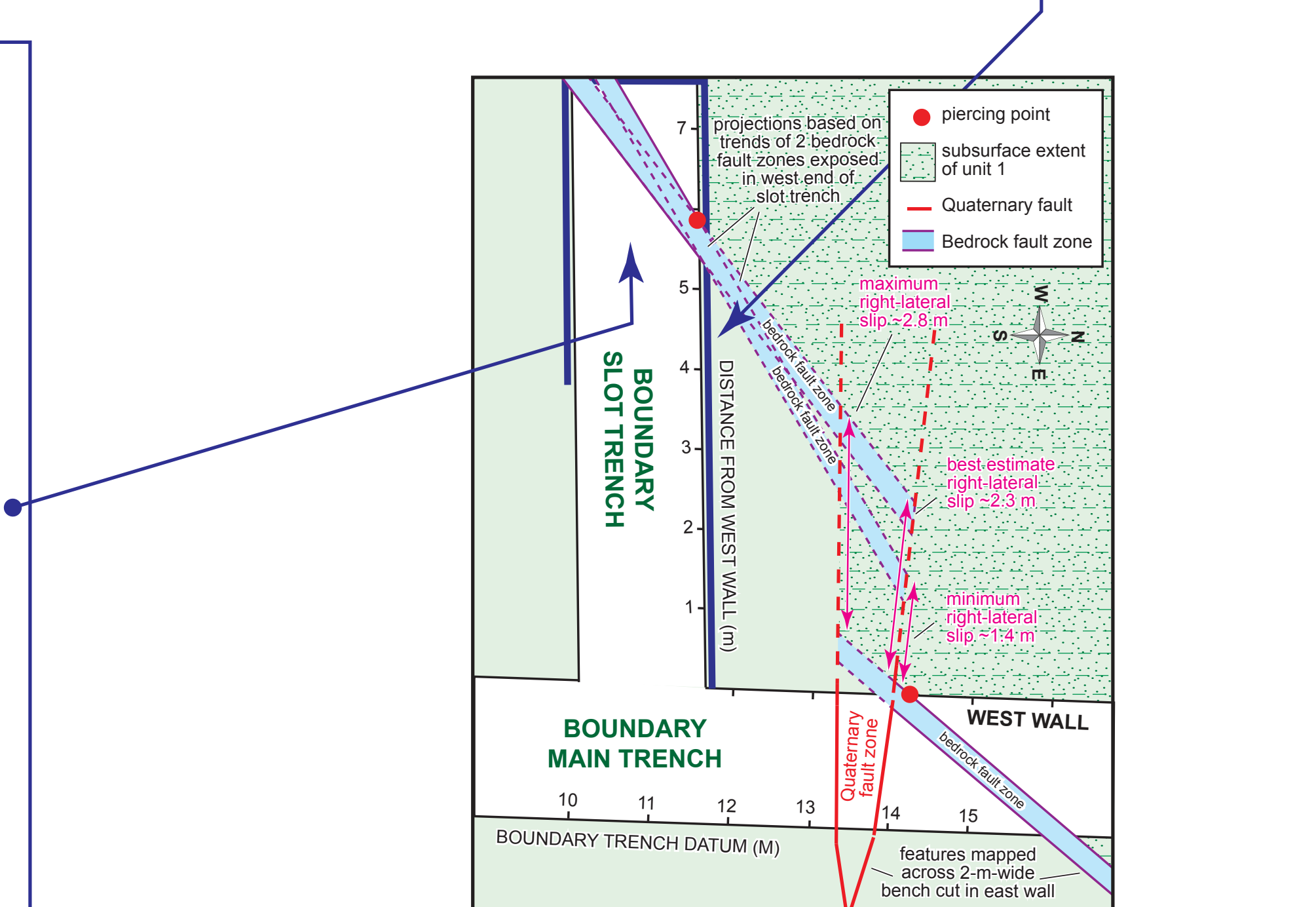

